\title{
SOBRE LA ODISEA CONSTITUCIONALISTA DE LUIGI FERRAJOLI*
}

\author{
Liborio L. Hierro \\ Universidad Autónoma de Madrid
}

RESUMEN. El ensayo de FERRAjol que aquí se comenta parece estar destinado a subrayar las diferencias que separan el constitucionalismo garantista del neo-constitucionalismo principialista. Para construir el constitucionalismo garantista FERRAJOLI proclamó la necesidad de abandonar totalmente el paradigma paleo-positivista pero, al hacerlo, se acercó peligrosamente a las tesis post-positivistas con las que quiere ahora marcar claras distancias. En este tránsito entre Escila y Caribdis, FERRAJOLI ha formulado una teoría jurídico-formal de los derechos fundamentales que se sitúan en un mundo jurídico-positivo de nivel superior y de carácter objetivo, al que todos los mundos jurídicos inferiores están supeditados y por el que están limitados; tanto la producción normativa inferior, incluida la legislación formal, como la aplicación jurisdiccional se mueven en un ámbito delimitado por lo que no se puede decidir y lo que no se puede dejar de decidir. A pesar de sus esfuerzos por evitarlo, el constitucionalismo formal de FERRAJOLI elude la cuestión de la última palabra y promueve el activismo, al menos el activismo de la jurisdicción constitucional.

Palabras clave: FerRAJoli, constitucionalismo, derechos fundamentales, democracia, objeción contramayoritaria.

ABSTRACT. Luigi FERRAJOLI's paper discussed here seems to be intended to underline the differences that separate the positivist or normative constitutionalism from the non-positivist or principle constitutionalism. To construct the normative constitutionalism FERRAJOLI proclaimed the need to totally abandon the paleo-positivist paradigm, but in doing so, came perilously close to the postpositivist thesis with which he now tries to keep clear distances. In this passage between Scylla and Charybdis, FerRAJOLI has formulated a formal legal theory of the fundamental rights which are in a positive-legal world of a superior level and with an objective character, to which all inferior legal worlds are subordinates and by which they are limited; both lower production rules, including formal legislation, and the judicial application move in a limited scope so for that you can not decide and for what can not be left to decide. Despite their efforts to prevent this, FERRAJOL's formal constitutionalism evades the question of the last word and promotes activism, at least the activism of constitutional jurisdiction.

Keywords: FERRAJOLI, constitucionalism, fundamental rights, democracy, counter-majoritarian difficulty.

* Fecha de recepción: 10 de enero de 2011. Fecha de aceptación: 7 de febrero de 2011. 


\section{MOTIVO DEL VIAJE}

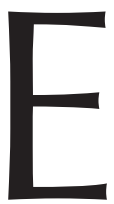

1 ensayo que Luigi FerRAJOLI nos ofrece para este nuevo debate convocado por la revista Doxa es un apretado resumen de su teoría constitucional a la que propone denominar «constitucionalismo garantista». La teoría de la constitución de Luigi FERRAJOLI, como es de sobra sabido, no constituye una parte de su teoría del Derecho sino que es su teoría del Derecho ${ }^{1}$. Si la Teoría Pura del Derecho de KELSEN — la «Reine Rechtslehre» de nuestros años jóvenes- pretendía ser una teoría general, completa y autónoma del Derecho, el «Constitucionalismo Garantista» pretende serlo del mismo modo; aquélla sería la teoría que culminó el paleo-iuspositivismo, teoría adecuada al Estado legislativo de Derecho, y ésta sería la teoría que abre una nueva etapa del positivismo jurídico, teoría adecuada al Estado constitucional de Derecho. No se habría producido — mirando así la cosa — una transformación del método de conocimiento sino más bien una transformación del objeto que se conoce ${ }^{2}$. Sería, por tanto, la transformación del Estado legislativo de Derecho en estado constitucional de Derecho el fenómeno histórico-social que nos obliga a abandonar aquella vieja teoría positivista del Derecho, que culminó en la Teoría Pura, para abrazar una nueva teoría positivista: el constitucionalismo garantista.

Ahora bien, con la publicación de sus Principia iuris parecía que Luigi FERRAJOLI había culminado su proyecto de formular el garantismo como teoría completa del Derecho del Estado constitucional. Por otra parte, toda su obra, desde Derecho y razón hasta los Principia iuris, ha sido objeto de amplios debates, especialmente en el ámbito latino ${ }^{3}$, por lo que no parece impertinente preguntarse por qué FERRAJOLI nos ofrece en este nuevo ensayo otro resumen de su teoría. El ensayo - me parece- no aporta contenidos nuevos en ningún aspecto; mi impresión es, por ello, que FERRAJOLI pretende dejar claro, por si no lo estaba, la distancia que separa al constitucionalismo garantista del neo-constitucionalismo post-positivista.

Puesto que hace ya mucho tiempo que Luigi FERRAJOLI se propuso hacer esa travesía desde el territorio paleo-iuspositivista, que encontraba reflejado paradigmáticamente en la obra de KELSEN y no en mucho menor grado en la de BOBBIO, para llegar a un nuevo territorio teórico en el que garantismo y constitucionalismo se fundirían necesariamente para constituir la teoría del Estado constitucional de Derecho, y puesto que ahora quiere subrayar la distancia que, sin embargo, le separa del neo-constitucionalismo en boga, me ha parecido ilustrativo reconstruir su travesía como el difícil

1 M. Gascón, 2005: 35; Ruiz Miguel, 2005: 211. El mismo FerRajoli anunció desde un principio el alcance «teórico y filosófico general» del garantismo (FERRAJOLI, 1995: 854).

2 Algo similar a lo que ya se suscitó en los años setenta del siglo pasado cuando algunas voces reivindicaron el paso de una teoría estructural del Derecho, en la que se incluía al positivismo tradicional y a la Teoría Pura, a una teoría funcional, paso que vendría requerido porque «las transformaciones que el estado y el Derecho han sufrido en el siglo Xx han convertido en inadecuados los conceptos elaborados por la teoría tradicional» (CALSAMIGLIA, 1979: 19) y que explicaría, en palabras de BoBBIO, «la imprevista emergencia y la rápida difusión de la perspectiva funcionalista» (BOBBIO, 1980: 265). Me parece curioso recordar ahora que también entonces sostuve que los defectos, por otro lado escasos, de la Teoría Pura estaban en la propia teoría y no venían obligados por los cambios en el objeto (HIERRO, 1981: 127).

3 L. Gianformaggio (ed.), 1993; L. Ferrajoli, L. Baccelli et al., 2001; M. Carbonell y P. Salazar (eds.), 2005; L. Ferrajoli, 2006; L. Ferrajoli, J. J. Moreso y M. AtienZa, 2008; y varios en Doxa, 31, 2008. 
trayecto entre Escila y Caribdis, lo que me permitirá luego plantear, como cuestión central, el bien conocido problema de las sirenas.

\section{ESCILA O LAS ABOMINACIONES PALEO-IUSPOSITIVISTAS}

El primer tramo de la travesía exigía huir de las amenazas del paleo-iuspositivismo que, como Escila, acechaba con sus seis horribles dogmas: coactividad, legalismo, imperativismo, coherencia, plenitud y logicismo interpretativo (RuIZ Miguel, 1980: 31). La hipótesis, formulada explícitamente por FERRAJOLI, era que este paradigma teórico nos impedía comprender la nueva realidad constitucional ${ }^{4}$. Algunos argumentos parecían especialmente aptos para confirmar esta hipótesis. Comentaré sólo tres de ellos, que me parece son a los que FERRAJOLI concede mayor relieve para justificar la necesidad de su travesía.

El primero es la distinción entre un deber ser constitucional del Derecho y un ser legislativo del Derecho, distinción que necesariamente se deriva de la configuración, en el paradigma constitucional, de diferentes niveles normativos, teniendo los más bajos un carácter fáctico respecto a los superiores y provocando, por ello, la presencia de antinomias y lagunas (FERRAJOLI, 2006: 28 y 2008 bis: 37 y 43) 5 . El segundo resulta una consecuencia inmediata del primero y estriba en la errónea teoría paleo-iuspositivista de los criterios para resolver antinomias normativas. De acuerdo con ella, los tres criterios clásicos -jerárquico, cronológico y de especialidad- operaban en términos similares derogando la norma superior a la inferior, la norma posterior a la anterior y la norma especial a la general. Vistos con los ojos de la nueva teoría las cosas son muy distintas; señala FERRAJOLI que los criterios cronológico y de especialidad tienen el carácter de meta-normas constitutivas y, por ello, inviolables, mientras que el jerárquico tiene el carácter de una meta-norma regulativa y, por ello, puede ser violada (FERRAJOLI, 2008 bis: 39 y 213) ${ }^{6}$. El tercero, finalmente, deriva en algún modo de los dos anteriores y consiste en la distinción, ignorada por el paleo-iuspositivismo, entre validez y vigencia, distinción que resulta necesaria para comprender cómo, bajo la estructura constitucional, podemos encontrar leyes vigentes que carecen de validez por ser contrarias a la constitución (FERRAJOLI, 2006: 60).

Como se puso de relieve en debates anteriores, en particular por José Juan MORESO (MORESO, 2008: 122 y 124), el problema de estos tres argumentos es que, siendo todos ellos acertados en los errores que constatan, no derivan exclusiva ni necesariamente del

${ }^{4}$ Con una formulación muy clara y rotunda en FerRAJOLI, 2008 bis: 216: «En definitiva, el sistema de categorías que nos ha proporcionado el paleo-iuspositivismo [...] no supera la prueba de su aplicación en el paradigma constitucional [...] el paleo-iuspositivismo debe ser radicalmente revisado».

5 En FerRAJOli, 2008 bis: 208, acepta la crítica de MORESO en el sentido de que la distinción vigenciavalidez no es patrimonio del Estado constitucional, aunque insiste en que KELSEN no extrajo las conclusiones que de ella se derivan e insiste, luego, en la originalidad de la distinción (ibid., 210).

6 Aunque ahora no me ocuparé de ello, es sabido que — según FERRAJOLI- es precisamente este problema el que confiere «un inevitable papel normativo a la teoría con respecto a su propio objeto» (FERRAJOLI, 2001: 196). FERRAJOLI ha insistido, desde hace mucho y repetidamente, en que la teoría del constitucionalismo garantista no es sólo descriptiva sino que también es crítica, proyectual, normativa o pragmática (FERRAJOLI en GIANFORMAGGIO, 1993: 462; FERRAJOLI, 2008: 31 —un trabajo original de 1998-; 2008 bis: 68 y 192; vid. también PISARELlo y García MANRIQUe en la «Introducción» a FerRAJOli, 2008 bis: 12-13). 
paradigma constitucional. No me parece, en efecto, que se pueda distinguir entre un deber ser constitucional y un ser legislativo del Derecho y no se pueda, al mismo tiempo, distinguir entre un deber ser legislativo y un ser reglamentario del Derecho, como tanto gustaba distinguir el Sr. Romanones ${ }^{7}$. La distinción entre aquel deber ser constitucional y este ser legislativo, nivel inferior al que FERRAJOLI atribuye con sorprendente artificio un carácter fáctico, no parece teóricamente distinta — creo- de la que se daría entre un deber ser legislativo y un ser reglamentario y, desde luego, las antinomias y las lagunas no han nacido al mundo jurídico por esa distinción de grado entre constitución y legislación. Los errores en la reconstrucción teórica de la forma en que operan los criterios jerárquico, cronológico y de especialidad, acertadamente señalados por FERRAJOLI, no se deben en absoluto al fenómeno histórico-social de la aparición de constituciones rígidas; son, por el contrario, simples errores teóricos. A ellos, por cierto, cabe añadir (contra, o más allá de, FERRAJOLI) que no siempre el criterio jerárquico opera de forma regulativa, sino sólo combinado con el cronológico, esto es: en la contradicción entre norma anterior superior y norma posterior inferior. Obviamente, cuando la norma superior es posterior deroga a la norma inferior, pero no la hace inválida durante el tiempo en que estuvo previamente en vigor. Finalmente hay que señalar que, ciertamente, la jurisdicción constitucional constituye —o debe constituir- una protección contra las leyes inconstitucionales pero que, cuando fracasa, puede dejar en vigor leyes inválidas. Pero cierto es, también, que la jurisdicción contencioso-administrativa (allí donde se desarrolló, como en España) constituye —o debe constituir- una protección contra los reglamentos ilegales. Y cierto es, del mismo modo, que, cuando fracasa, puede dejar en vigor reglamentos ilegales. En ambos casos el fracaso del control, bien sea porque nadie hace llegar a la correspondiente jurisdicción la cuestión de inconstitucionalidad/ ilegalidad bien sea por un error en el juicio, deja vigentes normas inválidas de tal modo que la posible divergencia deóntica entre validez y vigencia no es consecuencia de la supremacía de la constitución, sino de la jerarquía del ordenamiento (cuando está establecida) y del carácter imperfecto de los procedimientos de control.

Me parece, pues, que ni la distinción entre un deber-ser-jurídico-superior y un ser-jurídico-inferior (que no es sino otro nivel de deber-ser-jurídico) —distinción derivada de la ordenación jerárquica de un sistema jurídico-, ni las antinomias y lagunas que virtualmente se derivan de esa estructura jerarquizada — en cuanto las normas inferiores pueden eventualmente contradecir a las superiores o dejarlas sin el debido desarrollo cuando es jurídicamente exigido por ellas-, ni la divergencia deóntica entre vigencia y validez — derivada de la imperfección del control que puede generar, en cualquier escalón del ordenamiento jurídico, la vigencia de normas inválidas-, ninguno de estos tres argumentos se deriva de la aparición de constituciones rígidas en los sistemas jurídicos contemporáneos.

En consecuencia, los errores que el paleo-iuspositivismo pudiera cometer al abordar estas cuestiones no son errores derivados de la nueva experiencia constitucional sino errores en la propia teoría paleo-iuspositivista.

7 En atención a FERRAJOLI, y a otros posibles lectores no españoles, conviene indicar que D. Álvaro de Figueroa y Torres (1863-1950), primer conde de Romanones, fue un político liberal español, tres veces presidente del gobierno bajo el reinado de Alfonso XIII y en otras varias ocasiones ministro, presidente del Congreso y presidente del Senado. Se le atribuye tradicionalmente la frase: «iQue ellos hagan las leyes mientras me dejen hacer los reglamentos!». Su sentido jurídico-político no requiere mayor comentario. 


\section{CARIBDIS O LOS RIESGOS NEO-CONSTITUCIONALISTAS}

Lo cierto es que FERRAJOLI se situó de esta forma a la cabeza del neo-constitucionalismo europeo que, ya en 1989 cuando apareció la primera edición de Derecho y razón. Teoría del garantismo penal, era una orientación renovadora y pujante en el pensamiento jurídico occidental. Desde entonces hasta hoy, y muy particularmente en la primera década del siglo XXI, la obra de FERRAJOLI no ha dejado de suscitar entusiasmo y polémica, principalmente en el pensamiento jurídico latino, aunque, curiosamente, gran parte del esfuerzo polémico de FERRAJOLI ha estado dedicado a distanciarse enérgicamente de las tesis centrales de las corrientes mayoritarias en el neoconstitucionalismo, las que podemos denominar post-positivistas o anti-positivistas, lo que - como indiqué al principio- me parece que constituye el eje central del ensayo que es objeto de este comentario. Es decir, FERRAJOLI eludió con valor las amenazas de Escila para, a continuación, enfrentarse a los mucho más peligrosos riesgos de Caribdis: el objetivismo moral, la vinculación necesaria entre el Derecho y la moral, y el activismo judicial $^{8}$.

Es sabido que, desde un principio, FERRAJOLI había sido avisado de estos tres peligros por sus críticos. Unos habían indicado que, a pesar de su confesión constante de positivismo ${ }^{9}$, su teoría implicaba un cierto objetivismo ético que le hacía «criptoiusnaturalista», en palabras de Ermanno Vitale (Vitale, 2001 bis: 277 y 280); otros habían subrayado que su definición de los derechos fundamentales suponía un cierto «fundamentalismo», una especie de legalismo-ético en el que, si el Derecho no se fundía con la moral, al menos la moralidad de los derechos se positivizaba en los derechos fundamentales cercenando la supuesta capacidad crítica de la teoría garantista (MARTí, 2005: 365); finalmente no pocos denunciaron que el constitucionalismo garantista de FERRAJOLI era un constitucionalismo «fortísimo» que conducía de forma inevitable, a pesar de sí mismo, a un activismo judicial y a una devaluación de la democracia (PINTORE, 2001: 246; DE LORA, 2005: 259). Otra parte de sus críticos habían aprovechado el acercamiento de FERRAJOLI a estos peligros para intentar, como Caribdis, «succionar su barco entero» invitando a FERRAJOLI a dar el paso final hacia el neo-constitucionalismo post-positivista (GARCÍA FigueroA, 2005: 274; AtienZA, 2008: 216; ATIENZA, 2008 bis: 165$)^{10}$.

FERRAJOLI en este ensayo ratifica, en estas tres cuestiones, argumentos que ya había esgrimido antes aunque, al hacerlo, me parece que rectifica suavemente algún aspecto

${ }^{8}$ En el ensayo que ahora comento, FERRAJOLI discute - junto al riesgo de dogmatismo del cognoscitivismo moral, emparejado con la vinculación entre Derecho y moral, y el riesgo de activismo judicial, emparejado con el método de la ponderación - el riesgo de debilitamiento de la normatividad de la constitución, emparejado con la distinción entre principios y reglas. En mi comentario no voy a incluir este tercer aspecto por meras razones de economía expositiva.

9 FERRAJOLI siempre ha reafirmado su positivismo, entendido - a partir de la conocida distinción de Bоввіо — como aproximación al estudio del Derecho, y ha negado ser positivista tanto en el sentido ideológico como en el sentido teórico-jurídico (FERRAJOLI, 2008 bis: 169-170).

10 Algunos otros han hecho a FERRAJOLI invitaciones más limitadas o discretas; por ejemplo, José Juan Moreso, que defiende un positivismo incorporacionista, sólo invita a FERRAJOLI a que haga espacio en el garantismo a la objetividad moral (MORESO, 2008 bis: 132) y Luis PRIETO, uno de los autores españoles más cercanos al garantismo, que echa en falta en el garantismo un lugar para la teoría de la argumentación y, con ella, para la ponderación como método (Prieto, 2005: 53, y PRIETO, 2008: 352 y 353 in fine) . 
importante y, una vez más, elude una cuestión que, en mi opinión, resulta fundamental para la teoría y la práctica constitucional, a la que dedicaré el siguiente apartado. Frente al neo-constitucionalismo post-positivista, al que propone denominar «principialista»o «argumentativo» [tomando los adjetivos — como él mismo recuerda- de Luis PRIETO y Alfonso García Figueroa (Prieto, 1997: 65, y García Figueroa, 1998: 69)], que pretende restaurar una relación necesaria, o al menos necesaria en los sistemas constitucionales, entre el Derecho y la moral, el constitucionalismo garantista o «normativo» no admite, ni como tipo de sistema jurídico, ni como teoría del Derecho, ni como filosofía política, una conexión necesaria entre el Derecho y la moral. Acusa FERRAJOLI al constitucionalismo principialista de ser la «enésima versión insidiosa del legalismo ético» e incluso de convertirse en una «ideología no-liberal», aunque prudentemente admite que «más allá de la intención de sus autores». No creo, desde luego, que para sostener la tesis positivista de la separación —es decir, la no conexión conceptual entre Derecho y moral - sea necesario suscribir el no cognoscitivismo moral. En realidad, un no cognoscitivista, como FERRAJOLI o yo mismo, tiene que sostener la tesis de la separación pero la misma tesis puede —y, en mi opinión, debería — ser compartida también por un cognoscitivista ${ }^{11}$. Tampoco me parece acertado sostener que el cognoscitivismo moral —que, insisto, yo no comparto- conduce inevitablemente al absolutismo moral y alcanza su forma más coherente en la moral católica. Hay muchos cognoscitivistas, y otros objetivistas morales de variada condición metaética, que afirman la libertad como valor moral primario, al que otros valores quedan sub-ordinados, lo que no es anti-liberal ni incoherente, y creo que a ese grupo pertenecen la mayor parte de los neo-constitucionalistas principialistas. Pero tampoco es mi intención extenderme en esta complicada cuestión sino tan sólo subrayar que FERRAJOLI reafirma su posición no-cognoscitivista y separacionista y, con ello, su fidelidad, en este punto, al positivismo; como ya había sostenido FERRAJOLI antes, de forma explícita y con toda razón, la positivación constitucional de ciertos valores morales sigue siendo algo contingente y «decir que el "Derecho", en virtud de esta positivación, es únicamente el justo (o moral), siendo su moralidad una connotación de su "concepto", y que además el Derecho justo (o moral) es precisamente el que expresan nuestras constituciones, constituye [...] una mezcla de iusnaturalismo y de legalismo ético» (FERRAJOLI, 2006: 43).

Sobre el activismo judicial ha llovido mucho desde que FERRAJOLI, en 1998, pusiese el énfasis en que la constitución «cambia en segundo lugar la naturaleza de la jurisdicción y la relación entre el juez y la ley [...] impone al juez la crítica de las leyes inválidas a través de su reinterpretación en sentido constitucional o de la denuncia de su inconstitucionalidad» (FERRAJOLI, 2008: 31). Obviamente este es un argumento al que FERRAJOLI no ha tenido que renunciar si bien parece que en fechas más recientes el acento se sitúa en una sujeción «rígida» del juez a la ley (FERRAJOLI, 2006: 61) y en un distanciamiento crítico del método de la ponderación en favor de la subsunción (ibid.: 92 y 97$)^{12}$.

11 GARCÍA FIgUEROA propone una interesante combinación de la tesis cognoscitivista («existe un orden moral objetivo») y la tesis de la vinculación («existe una relación conceptual entre el Derecho y ese orden moral») en la que el iusnaturalismo deontológico y el positivismo cognoscitivista comparten la afirmación de la primera y el rechazo de la segunda (GARCÍA FIGUEROA, 2005: 269-273).

12 Es importante, creo, señalar la insistencia de FERRAJOLI en que ponderación y subsunción son, a fin de cuentas, similares en el plano epistemológico-jurídico que, para él, es fuertemente cognoscitivo y que, en el 
Yo suscribiría en conjunto todos estos argumentos pero queda pendiente un problema. El cognoscitivismo interpretativo que, cada vez de forma más rotunda, propugna FERRAJOLI supone que los derechos fundamentales incluidos en una constitución deben estar —y normalmente están — claramente determinados. Lo que queda para el legislador es establecer sus garantías, pero los derechos fundamentales no son en ningún modo disponibles para el legislador, ni para la jurisdicción, ni —claro estápara los particulares ${ }^{13}$. La indisponibilidad de los derechos implica, como condición necesaria, su determinación, su carácter definitivo y no prima facie ${ }^{14}$, y genera, como consecuencia, la imposibilidad de conflictos entre ellos. Que ello pueda llegar a ser así si se retoma «el programa ilustrado de Gaetano FILANGIERI y de Jeremy BENTHAM de una "ciencia de la legislación", integrándolo con el programa de una "ciencia de la constitución”, como la llamó Giandomenico ROMAGNOSI» es más que dudoso; que hoy por hoy no hay constitución alguna cuyos enunciados de derechos, en muchos o en todos los casos, no adolezcan de vaguedad o indeterminación, y que algunos o todos los derechos enunciados no puedan entrar eventualmente en conflicto con otros derechos, es, por el contrario, algo que no permite albergar duda alguna ${ }^{15}$. Y el problema sencillamente es quién tiene la última palabra sobre el alcance y la prevalencia de los derechos fundamentales cuando su alcance no es claro o cuando entran en conflicto.

escaso margen de discreción que queda al interpretar normas, tanto hay varios mundos constitucionalmente posibles para el juez constitucional como mundos legislativamente posibles para el juez ordinario, como afirmó contestando a MORESO (FERRAJOLI, 2006: 92 y 97).

En el trabajo que ahora comento FERRAJOLI es, si cabe, más contundente que nunca en este aspecto: «La idea de que las normas constitucionales no son normas rígidamente vinculantes [...] ha favorecido el desarrollo de una inventiva jurisprudencial puesta de manifiesto en la creación de principios que no tienen ningún fundamento en la letra de la Constitución [...] Paralelamente al debilitamiento del carácter vinculante de las normas constitucionales a pesar de su rigidez, se avala de este modo, a través de la contraposición del balanceamiento a la subsunción, el debilitamiento del carácter tendencialmente cognoscitivo de la jurisdicción, en el que reside su fuente de legitimación, y se promueven y alientan tanto el activismo de los jueces como la discrecionalidad de la actividad judicial [...] el paradigma garantista del constitucionalismo rígido requiere que el poder judicial sea lo más limitado posible y vinculado por la ley y por la constitución... la legitimidad de la jurisdicción se funda, a mi parecer, en el carácter lo más cognoscitivo posible de la subsunción y de la aplicación de la ley».

13 Dice FERRAJOLI «que los derechos fundamentales son indisponibles quiere decir que están sustraídos tanto a las decisiones de la política como al mercado. En virtud de su indisponibilidad activa, no son alienables por el sujeto que es titular [...] Debido a su indisponibilidad pasiva, no son expropiables o limitables por otros sujetos, comenzando por el Estado; ninguna mayoría, por aplastante que sea, puede privarme de la vida, la libertad o de mis derechos de autonomía» (FERRAJOLI, 2001: 32; en el mismo sentido, contestando a PINTORE, ibid.: 349-350 y 368). Naturalmente esto sólo puede sostenerse creyendo que no hay nunca nada que decidir sobre el alcance de un derecho fundamental y que nunca entra en conflicto con otro. Sobre la posición de FERRAJOLI respecto a los conflictos, vid. MORESO, 2008: 284, y un análisis más amplio en PRIETO, 2008: 340-351.

${ }_{14}$ Sobre la distinción entre derechos prima facie y, de un lado, derechos absolutos o, de otro, derechos finales o definitivos, vid. HIERRO, 2002: 67, nota 84.

15 En la nota 72 FERRAJOLI pone el ejemplo de la tortura para indicar que, según el constitucionalismo garantista, «la inmunidad frente a la tortura no consiente excepciones». Aceptando el argumento, lo que no queda resuelto es qué es y qué no es tortura. FerRAJOli dirá que hay que fijar un concepto dogmático de tortura, como tenemos fijado el concepto dogmático de «hurto» (FERRAJOLI, 2008 bis: 180); todos aceptamos que el concepto jurídico-dogmático de hurto, aun siendo de elaboración doctrinal, queda establecido por una decisión del legislador; incluso si lo que quiere el legislador es modificar un concepto que ha resultado de la elaboración jurisprudencial. La cuestión estriba, precisamente, en quién establece el significado y alcance de un concepto constitucional como el de «tortura»; ¿el legislador o el tribunal constitucional? 


\section{LAS SIRENAS O ¿̇A QUIÉN ATAMOS AL MÁSTIL?}

Esta cuestión no es, por supuesto, nueva. Ha sido objetada al constitucionalismo garantista de FERrAJOLI en repetidas ocasiones (VITALE, 2001: 64 y 71; BOVERO, 2001: 234-237; PinTORe, 2001: 263; De LORA, 2005: 252 y 259; GrePPI, 2005: 353-354; MARTÍ, 2005: 387-388; SALAZAR, 2005: 442). FERRAJOLI ha contestado varias veces (a VITALE en FERRAJOLI, 2001: 148; a Pintore, ibid: 323 -329 y 342; a De LORA y a GREPPI en FERRAJOLI, 2006: 95-96) pero me parece que siempre ha eludido la cuestión ${ }^{16}$.

La cuestión es que la democracia constitucional, a diferencia del llamado modelo de Westminster, implica la posibilidad de que los tribunales declaren la invalidez de una disposición legal por ser contraria a la constitución (el «control jurisdiccional de constitucionalidad») con lo que la mayoría parlamentaria queda, por así decirlo, maniatada por el carácter normativo de la constitución. El problema es que este carácter normativo, así garantizado, se traduce, en realidad no sólo y no tanto en estar limitado por lo que la constitución dice, sino también en estar limitado por lo que los jueces interpretan que la constitución dice y, al mismo tiempo, por la dificultad para reformar la constitución, reforma que se hace inevitable no sólo en el supuesto de que la mayoría parlamentaria no esté de acuerdo con lo que la constitución dice, sino en el supuesto de que simplemente no esté de acuerdo con lo que los jueces interpretan que la constitución dice. Control y rigidez resultan ser dos piezas coherentes entre sí de un mismo engranaje, aun cuando los norteamericanos, inventores del modelo, ya comprobaron, cuando quisieron introducir legislación social, hasta qué punto este engranaje entregaba el poder a los jueces a costa del parlamento.

Ya he señalado en alguna otra ocasión que, desde el punto de vista de los derechos, los muchos y diferentes argumentos que se utilizan para explicar y defender el modelo de la «democracia constitucional» —es decir: las dos restricciones a las decisiones de la mayoría que lo caracterizan- podrían reducirse básicamente a tres: a) que las restricciones son necesarias para garantizar los derechos de todos, derechos que la mayoría reconoce en el momento constituyente, contra futuras decisiones de la mayoría que pudieran desconocerlos o limitarlos; $b$ ) que las restricciones son necesarias para garantizar los derechos de algunos, algunos que son minoría, contra las decisiones de la mayoría que pudieran desconocerlos o limitarlos, y c) que las restricciones son necesarias para garantizar algunos derechos, los derechos de especial importancia para la propia estructura democrática de decisión, contra las decisiones de la mayoría que pudieran desconocerlos o limitarlos ${ }^{17}$.

${ }^{16}$ En mi opinión la formulación más brillante de esta objeción la hizo Anna PinTORE (PINTORE, 2001: 263) a la que FERRAJOLI respondió, sustancial y sorprendentemente, recurriendo a la dimensión descriptiva del garantismo: «se trata, en suma, de tesis explicativas, en absoluto normativas, dado que ofrecen únicamente una explicación de la estructura del Estado ("constitucional" y no simplemente "legislativo") de Derecho [...] Las cosas son así, independientemente de nuestras opciones filosóficas o políticas, y la teoría del Derecho sólo tiene la tarea de dar cuenta de ello» (FERRAJOLI, 2001: 342 y 350). Por qué en esta cuestión FerRAJOLI abandona el carácter paradigmático del constitucionalismo y la dimensión normativa de la teoría garantista es algo que resulta poco comprensible.

${ }_{17}$ Cabe argumentar también que las restricciones a las decisiones mayoritarias que se derivan de la rigidez y el control son simplemente consecuencias necesarias de adoptar una constitución de carácter normativo. Creo que éste es el argumento de FERRAJOLI, coincidente con el que aparece formulado en la conocida senten- 
Que se trata de garantizar los derechos de todos es el argumento que popularizó Jon ELSTER en su conocido libro de 1979 (Ulysses and the Sirens. Studies in Rationality and Irrationality). La mayoría constituyente, temerosa - como Ulises- de poder estar sometida en el futuro a tentaciones que la inciten a privarse ella misma de las ventajas de un mundo en que los derechos de todos están reconocidos y protegidos y el poder está depositado en las decisiones de la mayoría, se somete a sí misma a restricciones para garantizar que sus decisiones correctas de ahora no se vean modificadas por sus decisiones incorrectas en el futuro ${ }^{18}$. Un argumento que lleva a conclusiones similares y que, por ello, debe situarse también en este primer grupo es el que, por continuar con la comparación, afirmaría que a Ulises hay que atarlo, quiera él o no quiera, para que no intente tomar luego una decisión que en realidad no sería competente para tomar. Creo que ese es el argumento formulado por Ernesto GARZÓN VALDÉS —en unos pasajes, brevísimos pero de enorme influencia, que aparecen en un trabajo de 1989 titulado Representación y Democracia - al afirmar que los derechos forman parte de los bienes básicos que están dentro de un «coto vedado» porque «deben ser excluidos de la negociación y el compromiso parlamentario» (GARZÓN, 1993: 644). Lo que está dentro del coto vedado son determinados bienes básicos para cualquier plan de vida que no pueden quedar al albur de la negociación y el compromiso que son propios de la decisión mayoritaria en el diseño democrático. Una constitución puede «reconocer» o «declarar» esos bienes básicos, entre los que están los derechos humanos, pero no es ella la que los crea y los define sino que le vienen éticamente impuestos: «constituyen el núcleo no negociable de una constitución democrático-liberal [...] vale la prohibición de reforma [...] y el mandato de adopción de medidas tendentes a su plena vigencia» (ibid., 649).

El segundo argumento es el que señala que los derechos humanos deben ser especialmente protegidos frente al riesgo de que las decisiones de la mayoría desconozcan o limiten los derechos de las minorías ${ }^{19}$. No se trata de la mítica hipótesis de que Ulises sea hechizado por las sirenas y se autodestruya sino de la más plausible hipótesis de que, en caso de apuro, Ulises decidiera sacrificar un par de grumetes. Éste fue un argumento sostenido por KELSEN, entre otros muchos, e influyentemente reconstruido por Ronald DwORKIN. Dice DwORKIN que «la institución de los derechos [...] representa la promesa que la mayoría hace a las minorías de que la dignidad y la igualdad serán respetadas» y afirma, por ello, que «los derechos individuales son triunfos políticos en manos de los individuos» (DWORKIN, 1984: 303 y 37). Lógicamente si los derechos son «triunfos» («comodines») que cualquier individuo puede esgrimir con éxito contra cualquier decisión de la mayoría, las decisiones de la mayoría quedan limitadas por los derechos. La rigidez y el control no son más que los instrumentos institucionales

cia del juez Marshall, pero, en tal supuesto, hay que aportar argumentos filosófico-políticos para justificar por qué es mejor tener una constitución que no tenerla.

18 ELSTER denomina a esta estrategia como «precompromiso» (precommitment) y define su primer requisito en estos términos: «(i)To bind oneself is to carry out a certain decision at time $t_{1}$ in order to increase the probability that one will carry out another decision at time $t_{2} \gg$ (ELSTER, 1984: 39). Aunque ELSTER no se refiere directamente a los derechos, sí subraya expresamente que una buena parte de las instituciones típicas de las democracias modernas obedecen a la estrategia del «precompromiso»y, en particular, la de establecer una constitución dotada de cierta rigidez (ibid., 89, 94 y 102-103).

19 W. J. WALUCHOW considera que éste es el mejor argumento en favor de una declaración de derechos atrincherada constitucionalmente y lo denomina «argumento estándar» (WALUCHOW, 2009: 185-186). 
tendentes a garantizar el cumplimiento efectivo de esa regla del juego: que cuando alguien esgrima un derecho frente al criterio de la mayoría, el Derecho gana y la mayoría pierde.

El tercer tipo de argumentos, por fin, sería el de quienes defienden que las restricciones a las decisiones de la mayoría no se justifican para proteger los derechos de todos ni para proteger los derechos de algunos, sino que se justifican sólo para proteger algunos derechos. La rigidez y el control, para este tipo de argumentos, sólo se justificarían en relación con ciertos derechos que son constitutivos de las reglas del propio juego democrático: los derechos de participación política. Esto es lo que suele denominarse el «principio de Blackstone» porque fue enunciado por William BlACKSTONE, ya en el siglo XVIII, como limitación única de la soberanía parlamentaria: «Las leyes del parlamento derogatorias del poder de parlamentos posteriores no son obligatorias» (BAYÓN, 2003: 409, nota 11). En la discusión contemporánea este argumento ha sido defendido con éxito por John HART ELY en un libro de 1980 (Democracy and Distrust. A Theory of Judicial Review) en que se sostiene que el control judicial de constitucionalidad tiene como única justificación la garantía de las reglas del juego democrático ${ }^{20}$.

Con frecuencia se toma la regla que formuló James Bradley THAYER, en un artículo publicado en 1893 en la Harvard Law Review — una regla de auto-contención para los «los tribunales que enjuician los actos legislativos»- como el origen de una tradición que ha venido señalando la contradicción que el diseño de la democracia constitucional implicaría para el propio principio democrático al atribuir a un órgano no democrático la decisión sobre qué cabe y qué no cabe dentro de la constitución. Ya muy entrado el siglo XX, Alexander M. BICKEL publicó, en el año 1962, un libro titulado The Least Dangerous Branch: The Supreme Court at the Bar of Politics en el que da forma a la hoy denominada «objeción contra-mayoritaria» ${ }^{21}$. En las décadas posteriores esta línea argumentativa ha sido continuada, sobre todo, en la obra de Jeremy WALDRON (en particular, The Dignity of Legislation, de 1999) que ha obtenido una notable influencia. A partir de ahí cabe recopilar los argumentos que la objeción u objeciones contra-mayoritarias esgrimen, ordenándolos en relación con los argumentos favorables a las restricciones constitucionales que acabo de proponer.

Naturalmente la primera y más fácil objeción es la que se refiere a la metáfora de Ulises. Mientras Ulises es una persona que toma decisiones estratégicas respecto a sus propias decisiones futuras, una mayoría constituyente no es, en ningún caso, la misma mayoría legislativa (o constituyente) futura sobre la que se toman las decisiones. El

20 «[...] derechos de esta índole, explícitamente mencionados o no, deben sin embargo ser protegidos de manera estricta, porque son decisivos para el funcionamiento de un proceso democrático abierto y efectivo» (Ely, 1997: 133). La propuesta de ElY es que la falta de legitimidad democrática del poder judicial obliga a que su función de control constitucional se limite al arbitraje de las reglas del juego — vigilar el proceso de representación, mantener despejados los canales del cambio político y facilitar la representación de las minoríasmientras que la selección de valores sustantivos debe quedar en exclusiva atribuida al proceso democrático de decisión

${ }^{21}$ ELY sale vigorosamente en defensa de BiCKEL, frente a la sugerencia de que había vivido bajo la contradicción de ser «liberal» en cuestiones políticas y conservador en su concepción de la función judicial, afirmando que no hay tal contradicción ya que «es perfectamente posible ser un liberal auténtico en política y al mismo tiempo creer, por respeto al proceso democrático, que la Corte no debe intervenir en los juicios de valor de la legislatura» (ELY, 1997: 95). 
argumento de Ulises tiende a ocultar que, en el caso de las restricciones constitucionales, lo que más bien ocurre es que una generación establece restricciones sobre las decisiones de generaciones futuras ${ }^{22}$. Si, dejando al margen el argumento Ulises, nos referimos a la interpretación más seria del «coto vedado» la objeción principal estriba en que este argumento requiere una fuerte convicción cognoscitivista sobre la objetividad de los valores que, nuevamente, parece implicar que una generación impone sus convicciones morales «objetivas» sobre las generaciones futuras. El problema, en todo caso, estriba en que, aun admitiendo una hipotética zona clara de objetividad o consenso moral, las decisiones legislativas controvertidas nunca son las que se pronuncian sobre esa eventual zona clara sino las que se pronuncian sobre las zonas de penumbra que la rodean (los límites de la vida, los conflictos de derechos, las situaciones excepcionales, etc.) y en estas zonas de penumbra el problema sigue siendo a quien corresponde tener la última palabra. Es decir: aun admitiendo que haya una zona intangible dentro del coto vedado, el problema es que tenemos que seguir tomando decisiones sobre los límites de esa zona, lo que está dentro y lo que no está dentro de ella. Parecidos son los argumentos contra la idea de DwORKIN. Sería fácil convenir que, cuando alguien tiene un derecho, el derecho funciona como un comodín contra cualquier decisión mayoritaria sobre lo que la mayoría entiende como el bien común, así como contra cualquier tipo de cálculo utilitario o de preferencia política general; el problema, sin embargo, subsiste cuando el objeto de la controversia es precisamente si alguien tiene o no tiene un derecho. Decir que los derechos son límites a las decisiones de la mayoría sería aceptable, tanto en la formulación general del «coto vedado» como en la formulación particular de la «protección de los derechos de la minoría», pero no resuelve la cuestión cuando lo controvertido son precisamente los propios derechos ${ }^{23}$.

$\mathrm{El}$ argumento hoy más extendido es el que fue esgrimido por Jeremy WALDRON. Enunciado brevemente el argumento afirma que el derecho de participación política no es un derecho entre los demás sino algo así como el «derecho de los derechos» ${ }^{24}$. En estos términos, WALDRON no trata de justificar una rigidez o una protección especial de este derecho sino, muy por el contrario, trata de objetar cualquier restricción a las decisiones de la mayoría como una restricción de este derecho. Si el derecho de igual participación en las decisiones colectivas es la madre de todos los derechos, entonces no cabe justificar, en nombre de los derechos, las restricciones que como la rigidez y el control de constitucionalidad de la legislación lo que hacen es otorgar un valor desigual a la participación de unos sobre la de otros; en el caso de la rigidez, porque se prima la opinión de las minorías al requerirse mayorías cualificadas; en el caso del control, porque se prima la opinión de la mayoría de un pequeño grupo de jueces sobre la de las mayorías parlamentarias. Precisamente por eso el «principio de Blackstone» no

22 Es importante señalar que ELSTER fue perfectamente consciente de esta objeción a la que bautiza como «la paradoja de la democracia»: «...each generation wants to be free to bind its successors, while not being bound by its predecessors» (ELSTER, 1984: 93). Las críticas a la metáfora de Ulises son muy frecuentes; vid. WALDRON, 2005: 322; WALUCHOW, 2009: 232, o, entre nosotros, LINARES, 2008: 50-51.

23 Jeremy WALDRON ha denominado a esta objeción como el «misterio de Dworkin»; como WaLDRON señala «las personas discrepan acerca de qué derechos tenemos» (Waldron, 2005: 20).

24 WALUCHOW, por su parte, ha devuelto a WALDRON la crítica que éste lanzaba sobre DwORKIN (el «misterio de Dworkin») señalando como «dilema de Waldron» el hecho - bastante obvio- de que «el desacuerdo también puede extenderse al principio mayoritario mismo» (WALUCHOW, 2009: 350). 
requiere ni permite un blindaje de los derechos de participación política sino, sencillamente, mantener vigente el principio de la soberanía parlamentaria ${ }^{25}$.

\section{LLEGADA}

FERRAJOLI da por sentado que la rigidez es un «rasgo estructural» de las constituciones (FERRAJOLI, 2008 bis: 91-92) y no parece simpatizar con su cuestionamiento aunque, en el calor del debate, se incline por introducir una justificación aparentemente novedosa: no se trata, con la rigidez y el control, de atar las manos de las generaciones futuras para garantizar todos los derechos de las generaciones futuras: «las normas sobre la rigidez constitucional [...] sirven para garantizar el futuro de la democracia, de los derechos fundamentales, y con ellos precisamente, cualquier cosa que signifique este término, de la "soberanía popular" de las generaciones futuras; atando las manos, es cierto, a las generaciones en cada momento presentes, a fin de impedir que sean ellas las que amputen las manos a las generaciones futuras» (contestando a Pablo DE LORA, en FerRajOli, 2006: 107; en el mismo sentido, FerRajoli, 2008 bis: 96).

Algunos de sus críticos han insistido en que el argumento puede resultar «devastador» para la propia legitimidad democrática y para el principio moral de la autonomía que la sirve de justificación (PinTORE, 2001: 243; MARTí, 2005: 388, y SALAZAR, 2005: 442). Parece que, efectivamente, FERRAJOLI no sitúa ese principio ni aquella legitimidad como fundamentos de los derechos humanos y, por ello, rechaza con un argumento meramente retórico la objeción; retórico — digo — porque no cambia el problema al desplazar la presunta y discutible autoridad de una generación actual para atar las manos de las generaciones futuras a la igualmente presunta y discutible autoridad de una generación pasada (por cierto: ¿ cuál?) para atar las manos de la generación presente. Lo que permite a FERRAJOLI eludir, de esta retórica forma, el problema planteado es su convicción en el carácter definitivo de los derechos fundamentales enunciados constitucionalmente. Éste es el soporte aparentemente firme en que él se apoya pero, en este punto, se equivoca. Para decirlo en pocas palabras: en Itaca sigue habiendo graves problemas que resolver.

\section{REFERENCIAS BIBLIOGRÁFICAS}

AtienZA, M., 2008: «Tesis sobre Ferrajoli», en Doxa. Cuadernos de Filosofía del Derecho, 31, 213-216.

— 2008 bis: «Sobre Ferrajoli y la superación del positivismo jurídico», en FerRAJOLI, 2008 bis: $133-165$.

BAYÓN, J. C., 2003: «Derechos, democracia y Constitución», en LAPORTA (ed.), 2003, 399-422. Bellamy, R., 2007: Political Constitutionalism. A Republican Defence of the Constitutionality of Democracy, Cambridge, Cambridge University Press.

${ }^{25}$ Una excelente defensa de este enfoque se puede encontrar en un libro reciente de Richard BELLAMY. En sus propias palabras: «This book has defended democracy against judicial review. It has done so not on the grounds that democracy is more important that constitutionalism, rights or the rule of law, but because democracy embodies and upholds these values» (BELLAMY, 2007: 263). 
BobBio, N., 1980: Contribución a la teoría del Derecho, edición de Alfonso Ruiz Miguel, Valencia, Fernando Torres editor.

Bovero, M., 2001: Derechos fundamentales y democracia en la teoría de Ferrajoli. Un acuerdo global y una discrepancia concreta, en FERRAJOLI, 2001, 215-242.

Calsamiglia, A., 1979: Prólogo, en Kelsen, 1979, 7-21.

Carbonell, M., y Salazar, P. (eds.), 2005: Garantismo. Estudios sobre el pensamiento jurídico de Luigi Ferrajoli, Madrid, Trotta.

DE LORA, P., 2005: Luigi Ferrajoli y el constitucionalismo fortísimo, en CARBONELL y SALAZAR (eds.), 2005, 251-265.

Díaz, E., y Colomer, J. L. (eds.), 2002: Estado, justicia, derechos, Madrid, Alianza.

Dworkin, R., 1984: Los derechos en serio, Barcelona, Ariel (orig.: Taking Rights Seriously, London, Gerald Duckworth \& Co., 1977).

ELsTER, J., 1984: Ulysses and the Sirens. Studies in Rationality and Irrationality, Cambridge, Cambridge University Press (primera edición de 1979) (hay edición en español: Ulises y las sirenas. Estudios sobre racionalidad e irracionalidad, México, Fondo de Cultura Económica, 1989).

Ely, J. H., 1997: Democracia y desconfianza. Una teoría del control constitucional, Santafé de Bogotá, Siglo del Hombre eds. [orig.: Democracy and Distrust. A Theory of Judicial Review, Cambrigde (Mass.), Harvard University Press].

Ferrajoli, L., 1995: Derecho y razón. Teoría del garantismo penal, Madrid, Trotta (orig.: Diritto e ragione. Teoria del garantismo penale, Bari, Laterza, 1989).

- 2006: Garantismo. Una discusión sobre Derecho y democracia, Madrid, Trotta.

- 2008: Democracia y garantismo (edición de Miguel Carbonell), Madrid, Trotta.

Ferrajoli, L.; Baccelli, L.; Bovero, M.; Guastini, R.; Jori, M.; Pintore, A.; Vitale, E., y Zolo, D., 2001: Los fundamentos de los derechos fundamentales, en A. CABO y G. PISARELLO (eds.), Madrid, Trotta.

Ferrajoli, L.; Moreso, J. J., y AtienZA, M., 2008 bis: La teoría del Derecho en el paradigma constitucional, Madrid, Fundación Coloquio Jurídico Europeo.

García FigueroA, A., 1998: Principios y positivismo jurídico. El no positivismo principialista en las teorías de Ronald Dworkin y Robert Alexy, Madrid, Centro de Estudios Políticos y Constitucionales.

- 2005: Las tensiones de una teoría cuando se declara positivista, quiere ser crítica, pero parece neoconstitucionalista. A propósito de teoría del Derecho de Luigi Ferrajoli, en CARBONELL y SALAZAR (eds.), 2005, 267-284.

Garzón Valdés, E., 1993: Derecho, Ética, Política, Madrid, Centro de Estudios Constitucionales.

GASCÓN, M., 2005: La teoría general del galantismo, en CARBOnELl y SALAZAR (eds.), 2005, 21-39.

Gianformaggio, L. (ed.), 1993: Le ragioni del garantismo. Discutendo con Luigi Ferrajoli, Torino, Giappichelli (hay edición en español: Las razones del garantismo. Discutiendo con Luigi Ferrajoli, Bogotá, Temis, 2008).

GREPPI, A., 2005: Democracia como valor, como ideal y como método, en CARBONELL y SALAZAR (eds.), 2005, 341-364.

HierRo, L. L., 1981: «La Teoría del Derecho desde la estructura a la función», en Sistema, núm. 42 (mayo 1981), 119-127.

- 2002: El concepto de justicia y la teoría de los derechos, en DíAz y COLOMER (eds.), 2002, 11-73.

KeLSEN, H., 1979: Compendio de teoría general del estado, con estudio preliminar de L. RECASÉNS SiCHES y prólogo de A. CALSAMIGLIA, Barcelona, Blume. 
LAPORTA, F. J. (ed.), 2003: Constitución: problemas filosóficos, Madrid, Centro de Estudios Políticos y Constitucionales.

Linares, S., 2008: La (i)legitimidad democrática del control judicial de las leyes, Madrid, Marcial Pons.

MARTí, J. L., 2005: El fundamentalismo de Luigi Ferrajoli: un análisis crítico de su teoría de los derechos fundamentales, en CARBONELL y SALAZAR (eds.), 2005, 365-401.

Moreso, J. J., 2008: «Ferrajoli o el constitucionalismo optimista», en Doxa. Cuadernos de Filosofía del Derecho, 31, 279-287.

- 2008 bis: Sobre «La teoría del Derecho en el sistema de los saberes jurídicos» de Luigi Ferrajoli, en FERRAJOLI, 2008 bis,117-132.

Pintore, A., 2001: Derechos insaciables, en Ferrajoli, 243-265.

Pisarello, G., y García Manrique, R., 2008: Introducción, en Ferrajoli, 2001, 9-24.

PRIETO, L., 1997: Constitucionalismo y positivismo, México, Fontamara.

- 2005: Constitucionalismo y garantismo, en CARBONELL y SALAZAR (eds.), 2005, 41-57.

- 2008: «Principia Iuris: una teoría del Derecho no (neo)constitucionalista para el Estado constitucional», en Doxa. Cuadernos de Filosofía del Derecho, 31, 325-353.

Ruiz Miguel, A., 1980: Estudio preliminar. Bobbio y el positivismo jurídico italiano, en BOBBIO, 15-64.

- 2005: Validez y vigencia: un cruce de caminos en el modelo garantista, en CARBONELL y SALAZAR (eds.), 2005, 211-132.

SALAZAR, P., 2005: Los límites a la mayoría y la metáfora del contrato social en la teoría democrática de Luigi Ferrajoli, en CARBONELL y SALAZAR (eds.), 2005, 429-445.

VITALE, E., 2001: ¿Teoría general del Derecho o fundación de una república óptima? Cinco dudas sobre la teoría de los derechos fundamentales de Luigi Ferrajoli, en FERRAJOLI, 2001, 63-73.

- 2001 bis: Sobre la fundamentación de los derechos fundamentales entre iusnaturalismo y positivismo, en FERRAJOLI, 2001, 267-285.

Waldron, J., 1999: The Dignity of Legislation, Cambridge, Cambridge University Press.

- 2005: Derechos y desacuerdos, Madrid, Marcial Pons (orig.: Law and Disagreement, Oxford, Oxford University Press, 1999).

WALUCHOW, W. J., 2009: Una teoría del control judicial de constitucionalidad basada en el Common Law. Un árbol vivo, Madrid, Marcial Pons (orig.: A Common Law Theory of Judicial Review. The Living Tree, Cambridge, Cambridge University Press, 2007). 